\title{
Reposition of intruded permanent incisor by a combination of surgical and orthodontic approach: a case report
}

\author{
Ki-Taeg Jang* / Jung-Wook Kim** / Sang-Hoon Lee*** / Chong-Chul Kim**** / \\ Se-Hyun Hahn***** / Franklin García-Godoy******
}

\begin{abstract}
This report presents a case of a completely intrusive luxation of an immature permanent central incisor in a 7 years 9 months-old girl. Because there are severe intrusive trauma and cortical alveolar bone fracture, it was impossible to reposition with orthodontic or surgical method alone. The intruded tooth was repositioned to healthy alveolar bone level by using surgical extrusion and stabilization with sutures and periodontal pack. After healing of adjacent bone, the intruded maxillary central incisor erupted orthodontically by removable orthodontic appliance. It was moved from a high position to level of adjacent tooth in about 7 months. A radiograph was taken 6 months after ceasing forced eruption, which demonstrated minor root resorption, but the alveolar bone height had increased.
\end{abstract}

J Clin Pediatr Dent 26(4): 341-346, 2002

\section{INTRODUCTION}

$\mathrm{T}$ raumatic intrusive luxation, an occurrence common in the primary dentition, but one that occurs in only $3 \%$ of all mechanical injuries to the permanent dentition, is usually accompanied by

* Ki-Taeg Jang, DDS, MS, PhD, Assistant Professor, Department of Pediatric Dentistry, Seoul National University, Seoul, Korea, Visiting Faculty, Department of Restorative Dentistry, Tufts University School of Dental Medicine, One Kneeland Street, Boston, MA 02111.

** Kim, DDS, PhD, Full time instructor, Department of Pediatric Dentistry, College of Dentistry, Seoul National University, 28-2, yeongun-dong, Chongno-ku, Seoul 110-744, Korea.

*** Sang-Hoon Lee, DDS, PhD, Associate Professor, Department of Pediatric Dentistry, College of Dentistry, Seoul National University, 28-2, yeongun-dong, Chongno-ku, Seoul 110-744, Korea.

**** Chong-Chul Kim, DDS, PhD, Professor, Department of Pediatric Dentistry, College of Dentistry, Seoul National University, 28-2, yeongun-dong, Chongno-ku, Seoul 110-744, Korea.

***** Se-Hyun Hahn, DDS, PhD, Chairman of Department of Pediatric Dentistry, College of Dentistry, Seoul National University, 28-2, yeongun-dong, Chongno-ku, Seoul 110-744, Korea.

****** Franklin García-Godoy, DDS, MS, Professor and Head of the Division of Biomaterials, Department of Restorative Dentistry, Tufts University School of Dental Medicine, One Kneeland Street, Boston, MA 02111.

Send all correspondence to Dr. Ki-Taeg Jang, Department of Pediatric Dentistry, College of Dentistry, Seoul National University, 28-2 Yeongun-dong, Chongno-ku, Seoul 110-744, Korea.

Voice: 82-2-760-2682

Fax: 82-2-744-3599

E-mail: jangkt820@yahoo.com, jangkt@snu.ac.kr fracture of the alveolar process and soft tissue laceration, and has a poor prognosis. ${ }^{1-4}$ Common sequelae to the traumatic intrusion are ankylosis (replacement resorption), external root resorption, pulpal necrosis, inflammatory resorption. ${ }^{1,5}$

Historically, suggested treatment methods of intruded teeth have been spontaneous re-eruption, immediate surgical repositioning and fixation, orthodontic repositioning, and a combination surgical and orthodontic therapy. ${ }^{5}$

Andreasen ${ }^{3,4}$ and Hollan ${ }^{6}$ reported that spontaneous re-eruption was common in the primary dentition and the spontaneous re-eruption of permanent teeth occurred mostly in immature teeth and rarely in teeth with closed apices.

Skieller ${ }^{7}$ advocated immediate surgical repositioning, but Andreasen ${ }^{4}$ recommended immediate orthodontic traction, because immediate surgical repositioning may increase the possibility of root resorption and ankylosis. Taintor ${ }^{8}$, however, suggested leaving the tooth alone to allow for spontaneous re-eruption. If that failed, eruptive orthodontic force would then be applied.

Turley ${ }^{9}$ reported that immediate orthodontic traction should be applied in addition to surgical luxation in cases of severe intrusion because the tooth cannot erupt spontaneously and may become histologically ankylosed 5-6 days after intrusion.

In cases of complete intrusive luxation, it would be not feasible to bond an orthodontic button or bracket on the tooth directly and if there is cortical alveolar bone fracture, it was impossible to reposition with orthodontic or surgical method alone. 

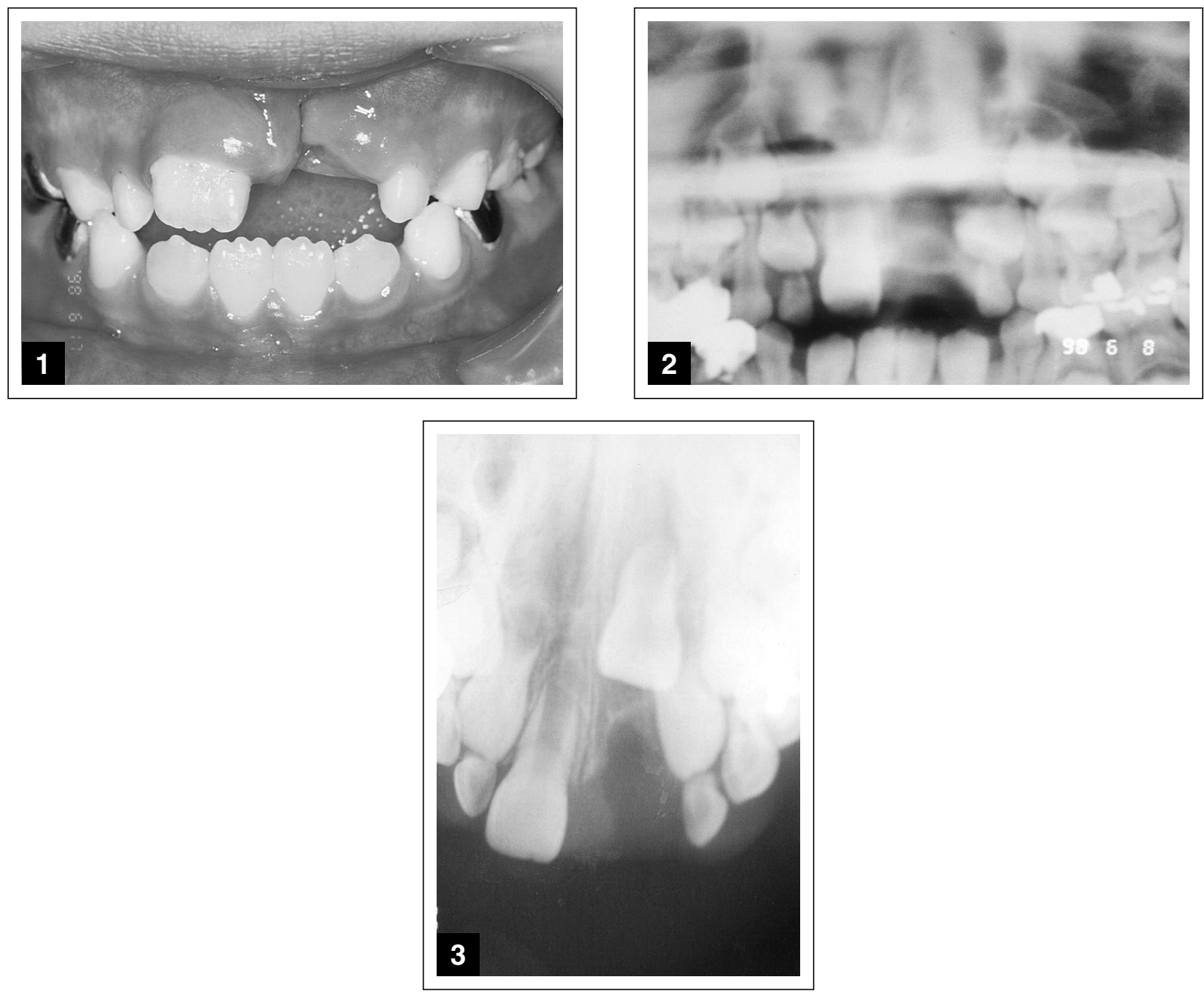

Figures 1 to 3 . Intraoral photo and radiographic image at examination one week after trauma.

\section{CASE REPORT}

A girl aged 7 years and 9 months was transferred to Seoul National Hospital Pediatric Dentistry Department. She had fallen down in the bathroom at home and injured herself 1 week previously. The initial impression at the local clinic was probable avulsion of left maxillary central incisor, lower lip laceration, upper labial and palatal laceration. However, clinical and radiographic examination revealed that left maxillary central incisor was intrusively luxated with cortical bone fracture (Figures 1 to 3 ). There seems to be intruded incisor in the floor of the nasal cavity in radiograph (Figures 2,3) but it was not observed clinically. There were no specific findings in physical and neurological assessment.

Because there were severe intrusion and cortical plate fracture, it was impossible to reposition with orthodontic or surgical method alone. It was decided to reposition the intruded left maxillary central incisor by combination of surgical and orthodontic methods.

The full flap was raised and the left maxillary central incisor was repositioned surgically to the healthy alveolar bone level (Figures 4 to 5), a button was bonded on it and the tooth splinted (Figure 6). After suturing, periodontal dressing was applied and a radiograph was taken (Figure 7). After 1 month, extrusive force was applied to the incisor using an elastic and a removable orthodontic appliance with palatal hook (Figure 8). The force to extrude the incisor did not exceed $20 \mathrm{~g}$.

Seven months later, the left maxillary incisor was positioned to level of adjacent tooth (Figures 9, 10). The application of extrusive force was stopped and 

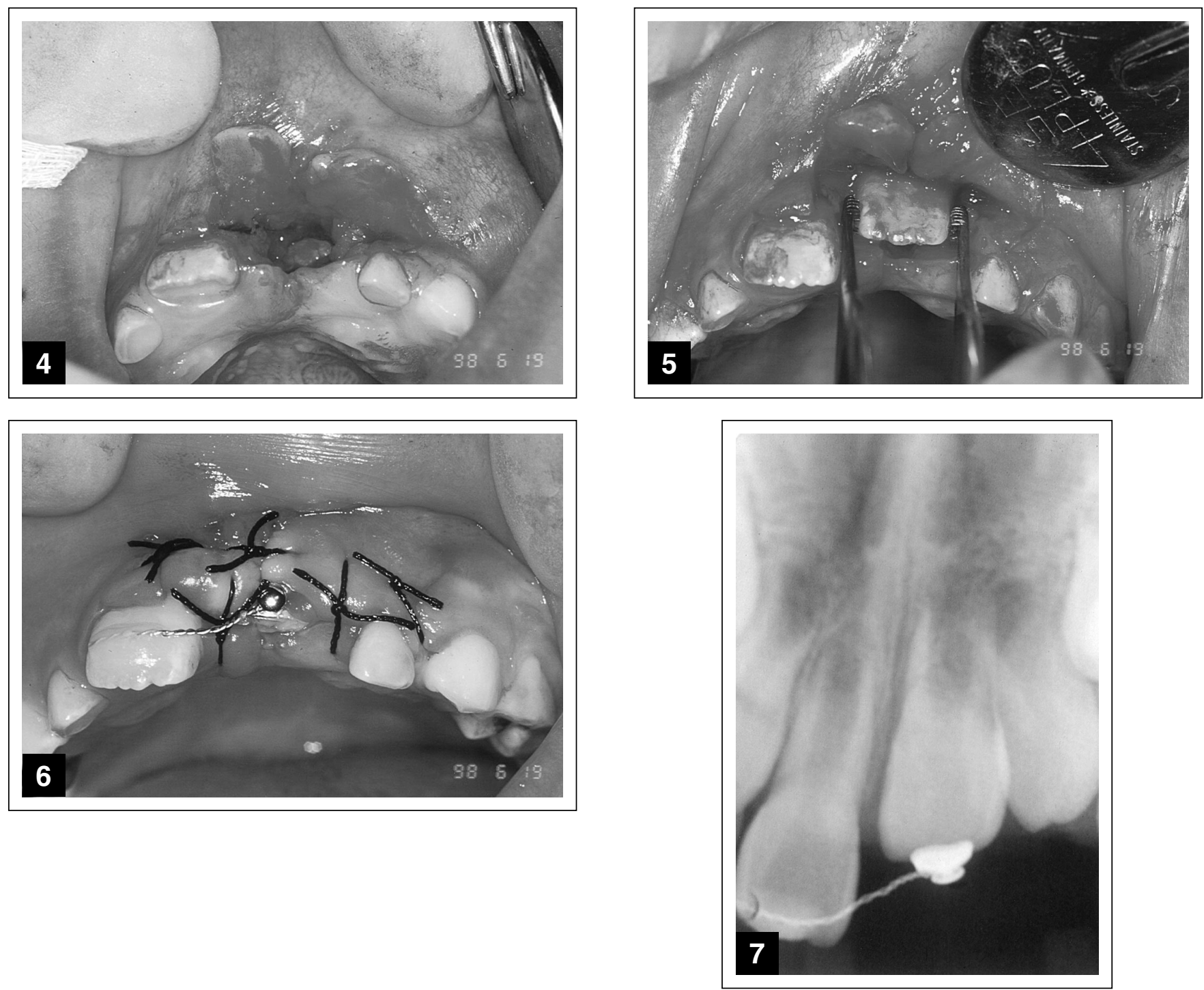

Figures 4 to 7 . The full flap was raised and left maxillary central incisor was repositioned surgically, a button was bonded on it and the tooth splinted.

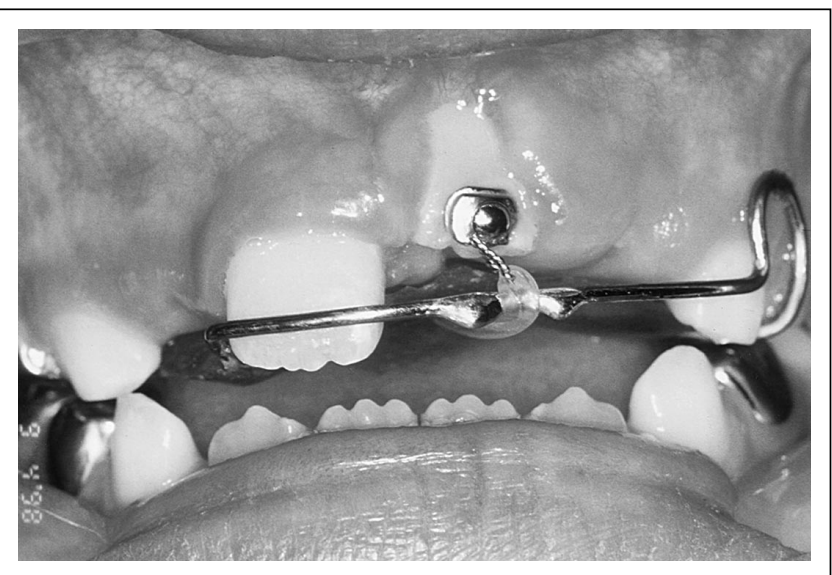

Figure 8. A removable orthodontic appliance was placed for the forced eruption of left maxillary central incisor. the bonded button was removed. A radiograph was taken 6 months after ceasing forced eruption, which demonstrated that the alveolar bone height had increased in the mesial area. However, there was minor root resorption and arrested root formation of the left maxillary central incisor (Figure 11). Endodontic treatment was postponed, as there were no discernable signs of pulpal inflammation or necrosis. 

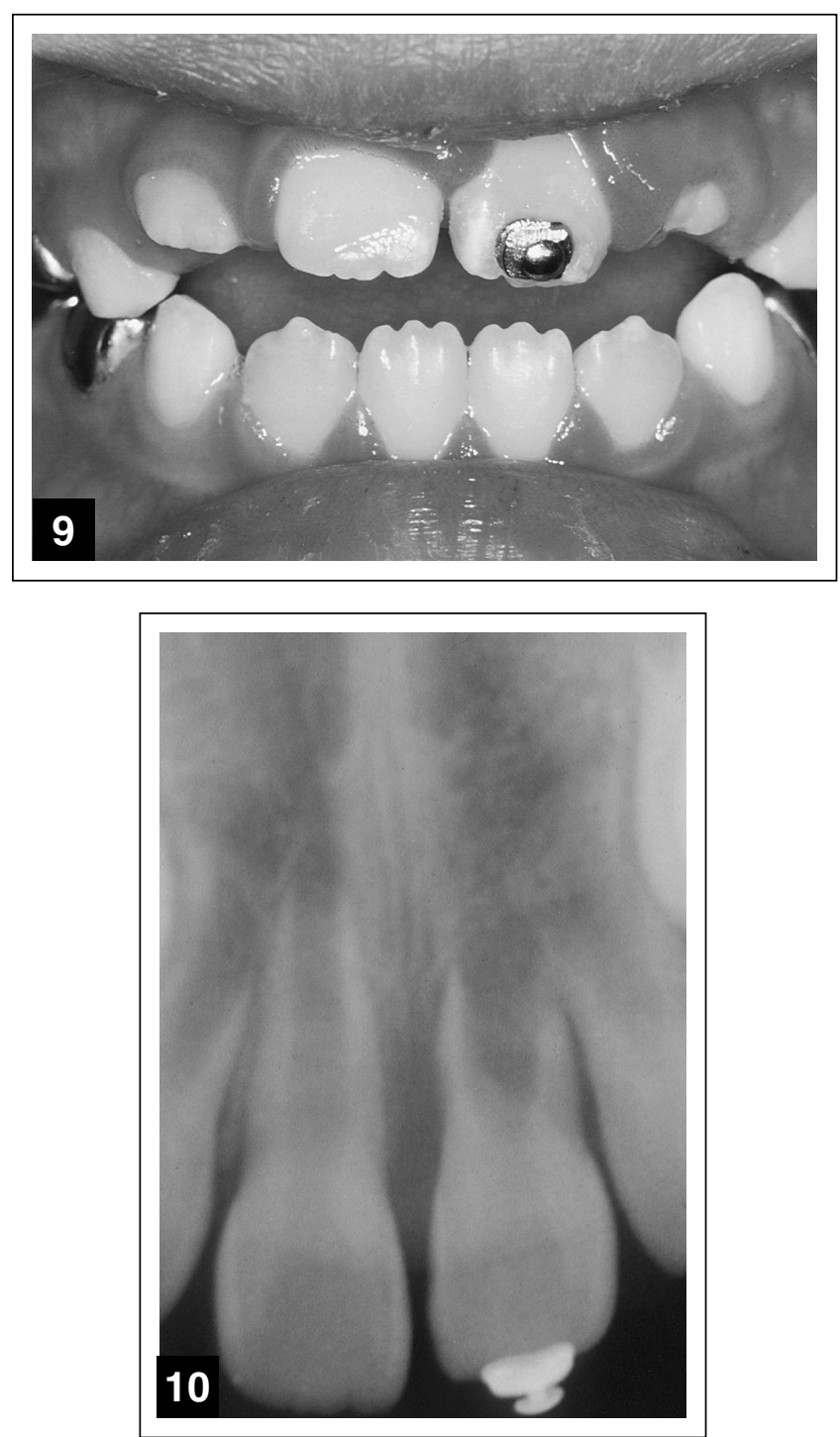

Figures 9, 10. Forced erupted left maxillary incisor to original position.

\section{DISCUSSION}

Andreasen ${ }^{14}$ and Saad $^{15}$ reported that it would not be desirable to reposition surgically since 'extensive marginal bone loss' would occur. In Andreasen's research, a replantation study using mature teeth of monkeys, splinting did not improve periodontal healing, but actually did the periodontal healing harm, i.e. ankylosis. Minoru ${ }^{16}$ reported that, in 13 patients from 9 to 17 years of age, who had impacted teeth, satisfactory results were obtained by applying orthodontic traction 2 to 5 months after repositioning the teeth still deep in the socket, without exposing the cemento-enamel junction. In particular, he claimed that satisfactory adjustment of supporting bony loss was observed following orthodontic treatment. Andreasen ${ }^{17,18}$ reported that periodontal membrane in the cervical area is regenerated mainly through supracrestal connective tissue, and this may have something to do with the adjustment mentioned above.

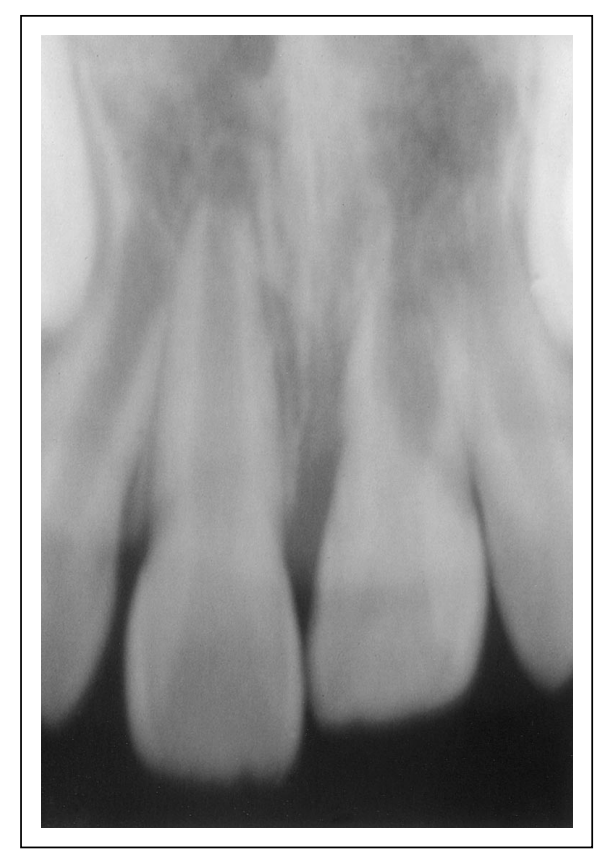

Figure 11. Six months later, radiography showed some root resorption and infra-occlusion.

In the present case, the reason for combination of surgical and orthodontic repositioning the tooth at the original site was that there is not enough surrounding alveolar bone. The intruded tooth was repositioned to healthy alveolar bone level by using surgical extrusion and stabilization. After healing of adjacent bone, the intruded maxillary central incisor erupted orthodontically by removable orthodontic appliance.

There was worry that the tooth might become ankylosed in spite of having been surgically repositioned before orthodontic treatment. Andreasen ${ }^{19}$ classified ankylosis into two types, temporary replacement resorption and permanent replacement resorption. Minoru ${ }^{16}$ reported that, in these cases, it would be mainly temporary resorption that occurred at the histological level, and successful repositioning would possible when started 2 to 7 months after the surgical procedure. 
In this case, orthodontic force was not applied immediately after surgical repositioning. The trauma of surgical repositioning causes total pulpal damage, which could be healed by various pulpo-dental reactions. ${ }^{20,21}$ Skoglund ${ }^{22}$ reported that after repositioning, initial revascularization started on the 4th day, extending into half the entire pulp cavity on the 10th day. By the 30th day, revascularization had extended into the entire pulp cavity.

Breivik $^{23}$ reported that reparative dentin could be observed in the apical third in as early as 2 weeks, suggesting it might be possible for the odontoblasts to survive after repositioning. According to Schatz, ${ }^{20}$ pulpal healing could decide the prognosis of endodontic treatment as well as pulpal healing. That is, help by coagulum existing after repositioning, reorganization by young connective tissue and reattachment of cementoenamel junction would be possible in 1 week and healing would be completed in 2 weeks.

The purpose of dis-impaction in this case was to decrease the chance of ankylosis and to minimize pressure necrosis of the periodontal ligament..$^{24}$ Biederman ${ }^{9}$ stated that the object of luxation was to break the bony bridge of ankylosis without injury to nutrient vessels at the apex.

With regards to endodontic treatment, Kristerson and Andreasen ${ }^{19,25}$ reported that surface root resorption could be stopped only if the tooth received endodontic treatment before pulpal necrosis. Minoru ${ }^{16}$ reported that root resorption could be arrested and asserted that it is not necessary to perform a preventive endodontic treatment in every case.

In the present case, endodontic treatment was postponed, as there were no discernable signs of pulpal inflammation or necrosis and it has been expected root growth. Further follow-up is needed to check root resorption and inflammation. Besides, if root resorption and extraction occur in the future, it was worth retaining the tooth as a space maintainer in this growing child.

\section{REFERENCES}

1. Oulis C, Vadiakas G, Siskos G. Management of intrusive luxation injuries. Endod Dent Traumatol 12: 113-19, 1996.

2. Mehmet K. Surgical extrusion of a completely intruded permanent incisor. J Endod 24: 381-84, 1998.

3. Andreasen JO. Etiology and pathogenesis of traumatic dental injuries. A clinical study of 1298 cases. Scand J Dent Res 78: 329-42, 1970.
4. Andreasen JO. Luxation of permanent teeth due to trauma. A clinical and radiographic follow-up study of 189 injured teeth. Scand J Dent Res 78: 273-86, 1976.

5. Turley PK, Crawford LB, Carrington KW. Traumatically intruded teeth. The Angle Orthodontist 57: 234-44, 1987.

6. Holan G, Ram D. Sequelae and prognosis of intruded primary incisors: a retrospective study. Pediatr Dent 21: 242-47, 1999.

7. Skieller V. The prognosis for young teeth loosened after mechanical injuries. Acta Odontol Scan 18: 171-81, 1960.

8. Taintor JF, Bonness PW, Biesterfeld RD. The intruded tooth. Dent Survey 55: 30-34, 1977.

9. Turley PK, Joiner MW, Hellstrom S. The effect of orthodontic extrusion on traumatically intruded teeth. Am J Orthodod 85: 47-56, 1984.

10. Paulo JM, Adriana RB. Treatment of an ankylosed central incisor by single-tooth dento-osseous osteotomy. Am J Orthod Dentofac Orthop 112: 496-501, 1997.

13. Jacobs SG. The treatment of traumatized permanent anterior teeth: case report and literature review. Part I-Management of intruded incisors. Aust Orthod J 13: 213-18, 1995.

14. Andreasen JO. The effect of splinting upon periodontal healing after replantation of permanent incisors in monkeys. Acta Odont Scand 33: 313-23, 1975.

15. Saad AY, Abdellatief EM. Surgical repositioning of unerupted anterior teeth. J Endod 22: 376-79, 1996.

16. Minoru H, Mikihiko K, Katsuhiko K. Clinical evaluation of orthodontic treatment after surgical repositioning or transplantation of teeth. J Nihon Univ Sch Dent 38: 123-30, 1996.

17. Andreason JO. Periodontal healing after replantation and autotransplantation of permanent incisors. Int J Oral Surg 10: 54-61, 1981.

18. Andreasen JO, Kristerson L. Evaluation of different types of autotransplanted connective tissues as potential periodontal ligament substitutes. Int J Oral Surg 10: 189-201, 1981.

19. Andreasen JO, Borum MK, Jacobsen HL, Andreasen FM. Replantation of 400 avulsed permanent incisors. 4. Factors related to periodontal ligament healing. Endod Dent Traumatol 11: 76-89, 1995.

20. Schatz JP, Byloff F, Bernard JP, Joho JP. Severely impacted canines: Autotransplantation as an alternative. Int $\mathrm{J}$ Adult Orthod Orthognath Surg 7: 45-54, 1992.

21. Cvek M, Cleaton-Jones P, Austin J, Lownie J, Kling M, Fatti P. Pulp revascularization in reimplanted immature monkey incisors-predictability and the effect of antibiotic systemic prophylaxis. Endod Dent Traumatol 6: 157- 69, 1990.

22. Skoglund A, Tronstad L, Wallenius K. A microangiographic study of vascular changes in replanted and autotransplanted teeth of young dogs. Oral Surg Oral Med Oral Pathol 45: 17-27, 1978.

23. Breivik M. Human odontoblast response to tooth replantation. Eur J Orthod 3: 95-108, 1981.

24. Kinirons MJ, Boyd DH, Gregg TA. Inflammatory and replacement resorption in reimplanted permanent incisor teeth: a study of the characteristics of 84 teeth. Endod Dent Traumatol 15: 269-72, 1999.

25. Kristerson L. Autotransplantation of human premolars - a clinical and radiographic study of 100 teeth. Int J Oral Surg 14: 200-213, 1985. 
